\title{
A critical examination of the Financial Mechanism as adopted in the Convention on Biological Diversity (CBD) from a developing country's perspective
}

Shah Md. Mushfiqur Rahman ${ }^{*}$

\section{Introduction}

\subsection{Objective}

The main objective of this article would be to examine the financial mechanism of the CBD for the purpose of measuring its efficiency to ensure the Convention's implementation in the developing countries. The more international environmental law advances the more it is realized that normative provisions are hardly able to bring any good to the environment, if it is not substantiated by effective compliance mechanisms. The Convention on Biological Diversity is no exception to this realization and in tune with that the CBD adopted some in-built mechanisms e.g. financial mechanism, technology transfer etc. But how much is the financial mechanism, the most important of these, efficient to prompt the developing countries to comply with the Convention? This article will search for the answer to this question which is especially intriguing given the challenge of developing countries to strike a balance between developmental and conservation needs.

\subsection{Importance}

Over the last few decades the world community has come to realize that the environment is such a transcending and crosscutting issue that any degradation or peril to it is capable of impacting every inhabitant of the planet. Therefore, collective and concerted effort to ensure the success of conservation attempts is necessary and this is not possible without the fullhearted and proper involvement of the third world countries. This is more so while it comes to biodiversity as many of the countries that are the richest in biological diversity are also amongst the poorest countries in the world. Obviously, developing countries are not placed in the same position as the developed countries in terms of implementing international responsibility conferred upon by different environmental instruments. So, to impose 'undifferentiated' responsibility upon the countries without considering their respective capabilities will potentially leave an environmental treaty of global magnitude e.g. the CBD totally futile. Given this aspect of implementation,

\footnotetext{
${ }^{*}$ Ex Senior Lecturer in the Department of Law, NUB. Now working with a Corporate House as Legal Adviser. Email: mushfiqur.rahman@alicobd.com
} 
the recent trend is to provide a number of incentive mechanisms intended to offer a 'preferential ground' for the developing countries. The same observation applies to the Convention on Biodiversity. It contains several inbuilt mechanisms, a good number of which are directed to the aim of ensuring its compliance by the developing countries. But even after one and a half decades of being put to real observance, we are still to witness any tangible development or hope for any potential development. So it is worthwhile to examine their feasibility from both theoretical and practical viewpoint.

As the recent environmental treaties are taking almost the same techniques of incentive mechanisms, more often than not using the same phraseology, a critical examination of CBD will provide us with a panoramic view of the other environment regulating Conventions as to how far they are efficient to ensure the compliance by the third world countries and what more needs to be done. As for this article, I'll focus on one particular mechanism adopted in the $\mathrm{CBD}$ and that happens to be its financial mechanism.

\subsection{Organization of the article}

At the outset, this article shall explore the justification of the emergence of financial mechanism as a compliance mechanism. Such emergence was more of a manifestation of a tug-of-war between developed and developing countries on environmental issues. Developing countries were not ready to take equal responsibilities as their developed counterparts because developed countries account for most of the environmental destructions and only they can afford the financial costs required to comply with the responsibilities under environmental treaties.

Then, different institutional structures employed for the operation of financial mechanism would be discussed. This would be followed by the background and development of the financial mechanism as a compliance mechanism to implement international environmental instruments. It would be observed that this really is a relatively recent phenomenon and the CBD happens to be one of the pioneering Conventions responsible for its present shape.

At this point the provisions of the CBD regarding its financial mechanism would be discussed at length. An array of issues will be covered ranging from the recognition of the principle of common but differentiated responsibility that prompted the adoption of the financial mechanism in the CBD, NorthSouth debate on additional funding, arguments on different proposals for 
collection of funds to institutional structure of the financial mechanism. After a prolonged debate, the GEF (Global Environment Facility) was settled to be the institutional structure of the CBD's financial mechanism. The deficiencies of the GEF will be discussed in the next part of the article with special emphasis on the interrelation between the GEF and the CBD Conventions of the Parties (COP).

The potential of private sector's involvement in bio-protection is discussed at the end with some proposed avenues for such involvement and their possible demerits. The article concludes with some general observations that are not only unique to the implementation of the CBD but also capable of being applied to other environmental instruments.

\section{Financial Mechanism}

\subsection{Provision of financial resources as a compliance mechanism}

When the effects of global environmental degradation in the shape of ozone depletion, global warming, loss of biodiversity and pollution of international water courses became increasingly apparent, industrial countries, which mostly account for the global pollution, had to accept a special responsibility to address the problems. Still, remedial actions taken by the countries belonging to the developed world were not enough to redress them and active involvement of the third world countries appeared to be imperative. The latter, however, were unwilling, if not unable, to shoulder this 'uncalled-for' burden. Moreover, most of them were quite reluctant to allow transboundary and global environmental problems any room in their national politics and development plans, only unless additional funds from the industrial countries were made available. In order to reach an international consensus, provision of additional financial support became not only necessary but also imperative. ${ }^{1}$

\subsection{Institutional structure of financial mechanism}

Particularly in the International Law of Environment, the provision of international financial resources through financial mechanism has two main aspects. The first concerns the extent to which overseas development assistance (ODA) granted bilaterally by states (or collectively by a group of states) or by international organizations. The second relates to the body of

\footnotetext{
${ }^{1}$ Streck Charlotte, The Global Environment Facility, a Role Model for International Governance?, Global Environmental Polities, May 2001
} 
international institutional and substantive law that has arisen out of the establishment and development of international mechanisms to provide financial assistance for global environmental objectives. These institutions vary in their expansions, scopes and activities. Some presents a comprehensive set of works like assessing compatibility of proposed projects vis-à-vis feasibility criteria, funding, monitoring and evaluating etc. Some are rather narrower in their scope. These institutions include the Global Environment Facility (GEF) and the Montreal Protocol Multilateral Fund, as well as earlier mechanisms such as the Wetlands Fund, the World Heritage Fund, and the International Fund for Plant Genetic Resources.

\subsection{Background and development}

Two events proved to be crucial for the creation of a new 'green' fund: The publication of the report of the World Commission on Environment and Development, 'Our Common Future' (1987); and the signing of the Vienna Convention for the Protection of the Ozone Layer (1985) and the more detailed Montreal Protocol on Substances that Deplete the Ozone Layer (1987). ${ }^{2}$ Later, the establishment by the 1990 Amendments to the Montreal Protocol of a financial mechanism to address ozone depletion marked an important turning point in the evolution of the international environmental law leading to further development and expansion of rules on finance. ${ }^{3}$ These events triggered the drafting of early proposals for a new fund for the global environment by nongovernmental organizations (NGOs), multilateral organizations and governmental actors.

As a mechanism, financial assistance got comprehensive recognition by Agenda 21 adopted as one of the major instruments at the UNCED. Section IV (Chapters 33-40) identifies some eight 'Means of Implementation'. 'Financial resources and means' takes the first place in number. We can easily substitute the term 'mechanism' for 'means' for the purpose of the present article.

\section{Financial Mechanism as envisaged in the CBD}

Articles 20 and 21 provide for the allocation of financial resources and establish a financial mechanism to provide new and additional financial

\footnotetext{
${ }^{2}$ Ibid

${ }^{3}$ Philippe Sands, Principles of International Environmental Law, Volume I, 1995
} 
resources to enable developing-country parties to meet the agreed full incremental costs for implementing the Convention.

From the very beginning of the negotiations, it was agreed almost unanimously that substantial financial means would need to be transferred to developing countries for conservation purposes if the Convention had to have any chance of being effective. Clearly, developing countries would have been left completely unable to meet their obligations under the Convention without such financial assistance. This recognition of common but differentiated responsibility principle is evident in the constant use of the expression, "as far as possible and as appropriate", throughout the Convention. But this recognition helped little to introduce any innovative financial mechanism or to motivate developed countries to provide additional funding above the existing aid, which was a demand of the South, led by the Group of 77 . The North, led by the Group of 7, on the other hand, was extremely reluctant to commit any new funding. ${ }^{4}$ Nevertheless it was somewhat of a victory for the developing countries that provisions on provision of financial resources, which would be 'additional', were enshrined in the text of the Convention.

During the negotiations various financial mechanisms for the Convention were suggested, although the problem was not studied in any depth until a relatively later stage. The original proposal was put forward by IUCN. ${ }^{5}$ It advocated that conservation actions should be financed through levies on the commercial applications of wild products, which would be paid into an international conservation fund established under the Convention. But this potentially effective suggestion failed to retain. Similarly, the possibility of creating an 'enterprise' for the commercial exploitation of genetic material, of which States would be shareholders, was not seriously investigated. ${ }^{6}$

After a superficial consideration of these initial proposals for comparatively innovative mechanisms, the Convention took a rather conventional solution to establish a financial mechanism with typical structure, which would have to be exclusively based on compulsory or voluntary contributions by

\footnotetext{
${ }^{4}$ Saleemul Huq and A. Atiq Rahman, Environment and development leakages: an international perspective, Environment and Development in Bangladesh, Volume 1, A. Atiq Rahman, Saleemul Huq et. Al (ed), 1994

${ }^{5}$ Cyrille de Klemm, in collaboration with Clare Shine, Biological Diversity Conservation and the Law - Legal mechanisms for Conserving Species and Ecosystems, IUCN, 1993

${ }^{6}$ Ibid
} 
Contracting Parties. This immediately raised doubts as to whether such contributions could ever be availed or, if availed, would be sufficient to meet global conservation requirements under the Convention. Our past experience with respect to such compulsory or voluntary contributions provides ground for this doubt.

But there are some elements in the Convention for the optimists too. Whenever an international treaty of global magnitude asks for developed countries' financial help in implementing that treaty, it immediately creates apprehension that those countries, if in any case they fulfill their obligation, will correspondingly reduce their other development assistance to the third world countries. So to keep this apprehension away, the Convention enacts that the developed country Parties shall provide new and additional financial resources to enable developing country Parties to meet the agreed full incremental costs, which they would incur in fulfilling their obligations under the Convention.

The Convention identified another group of countries, which neither falls within the category of developed countries nor developing countries. These are countries undergoing the process of transition to a market economy. They were given the option either to voluntarily assume the obligations of the developed country Parties or to abstain from taking any financial obligation under the Convention.

To systematize developed countries' financial obligation under the CBD, Article 20 provides that the Conference of the Parties (COP), shall at its first meeting establish a list of developed country Parties and other Parties, which voluntarily assume the obligations of the developed country Parties. The COP shall periodically review and, if necessary, amend the list.

Various methods were provided for the purpose of channeling the financial resources rather than preferring any uniform method. Financial resources to developing country Parties to meet the full incremental costs are to be agreed between a developing country Party and the institutional structure, referred to in Article 21, to be established by the first meeting of the COP. Another method suggests that the developed country Parties may also provide, and developing country Parties avail themselves of, financial resources related to the implementation of this Convention through bilateral, regional and other multilateral channels. 
What is significant with respect to the financial mechanism is the fact that the implementation of the developing country Parties' obligations is linked with the effective implementation by the developed country parties of their financial commitments under the Convention. ${ }^{7}$ The legal consequence to be followed is that without the provision of such resources, developing countries are considered by the Convention no longer bound by their conservation obligations.

There was considerable opposition between developed and developing countries during the negotiations as to the institutional structure of the financial mechanism. The former favored the Global Environmental Facility (GEF), already instituted jointly by the United Nations Development Programme (UNDP), the United Nations Environment Programme (UNEP) and the International Bank for Reconstruction and Development (IBRD). The developing countries felt that this institution lacks democracy and transparency and a separate structure should instead be instituted under the Convention, which would be under the direct control of the Conference of the Parties. ${ }^{8}$ The manner in which the projects have been selected, funds have been allocated and disbursed by the GEF had also raised criticism and there was hardly any open discussion. The whole programme was being run out of the World Bank funds in Washington DC and even the partner organizations, the UNEP and the UNDP, were feeling that they were not being consulted sufficiently. ${ }^{9}$

In search of a delicate balance it was decided that the GEF will serve as the required institutional structure on an interim basis, "provided it has been fully restructured" in accordance with the requirements that the Convention lays down with regard to democracy and transparency. Apart from governance problem, another issue came to the deep concern of the developing countries regarding the GEF. The main areas of its operation had been very limited so far. However, according to two Bangladeshi environmentalists, ${ }^{10}$ the developing countries managed to get some concessions about the inclusion of

\footnotetext{
${ }^{7}$ Art. 20(4) runs as follows, "The extent to which developing country Parties will effectively implement their commitments under this Convention will depend on the effective implementation by developed country Parties of their commitments under this Convention related to financial resources and transfer of technology..."

${ }^{8}$ Supra Note 5

${ }^{9}$ Supra Note 4

${ }^{10}$ Ibid
} 
more areas for funding and more openness and transparency in the governance of the organization and its activities, particularly regarding the selection of projects for funding. How far this optimism turned out to be true will be discussed later in the present article.

\section{Evaluation of the Mechanism}

\subsection{Deficiencies of the GEF as regards the CBD implementation}

The creation of the GEF was driven by a small number of EU countries. There was increasing pressure exerted by environmentally concerned voters who forced their governments to act. ${ }^{11}$ Next to this, European countries anticipated the system of international environmental treaties, which could create ground for more financial mechanisms. It was therefore rather a tactical move to establish the GEF and to preempt new proposals, which were likely to emerge from the UNCED in the following year. ${ }^{12}$ They tended to avoid the repetition of the model of the Multilateral Fund for the Montreal Protocol (MFMP). The Parties to the Montreal Protocol had been able to set up a financial mechanism to which donor countries were expected to contribute, and over which developed and developing countries shared power. Such a mechanism has the benefit of clearly demarcating donor country contributions to each treaty and would have ensured the dominance of each agreement's one country one vote governing body in financing decisions. ${ }^{13}$ However, donor countries feared an increased demand for financial resources by a proliferation of funds. So they preferred the GEF as a single financial mechanism for all Conventions, which would ensure their influence and control. When it was set up, many G77 countries saw the GEF as simply another source for development financing. They could never prefer a financial structure for the CBD and the UNFCCC, which is under the clear domination of the World Bank. Firstly, because of the control the Bank already exercises on the financial policies of many of these countries and secondly because many of them doubted the ability of the Bank to address environmental issues. They feared that the GEF could become an instrument for imposing "green" conditionality to World Bank loans. ${ }^{14}$ As a consequence of this North-South debate, the G77 had to reluctantly accept the GEF as the

\footnotetext{
${ }^{11}$ Supra Note 1

${ }^{12}$ Horta Korinna, Global Environment Facility, 1998

${ }^{13}$ Wericsman Jacob, Consolidating Governance of the Global Commons: Insights from the Global Environment Facility, 1995

${ }^{14}$ Gupta Joyeeta, Unpublished manuscript Washington, DC, 1995
} 
financial mechanism for the CBD and the UNFCCC on an interim basis subject to the condition that it would promote further transparency, democracy and universality of participation.

Though some restructuring attempts have already been undertaken, the major donor countries are still the most influential stakeholders in the system. First, they occupy their own seat on the GEF Governing Council. Second, they have at their disposal the means for staffing and coordination of their work on the Council. Some developing countries lack both the financial resources and knowledge to coordinate their interests. Another example of imbalance in terms of power and influence can be found among the Implementing Agencies. The tripartite partnership was an 'innovative' concept that already troubled a lot. However, the World Bank continues performing the most influential part and often leaves the other two agencies under-represented, if not unrepresented.

\subsection{The interrelation between the GEF and the COP}

The CBD and the UNFCCC are the lifelines of the GEF and they also provide it with a framework of legitimacy. At the same time, eligibility for GEF grants provides a strong incentive to ratify the Conventions. The approval of funding can also be used as a tool to bring countries into compliance with their commitments under the respective Conventions. In spite of this interdependence, the relationship between the COPs and the GEF has never been easy. The problems are due to the situation of double leadership of the GEF. ${ }^{15}$ On one hand the GEF has its own governance structure with a powerful Governing Council. On the other hand it works in the areas covered by the Conventions under the guidance of the respective COPs, which is not frequently translated into concrete measures. The priorities of the COPs and the GEF also are not necessarily the same, and in some cases they even contradict each other. ${ }^{16}$ If tension arises, the developing countries would prefer the Conventions to control the relevant parts of the GEF. The major donors would prefer to have control over the contentious issues and would prefer the GEF Council to exercise control. ${ }^{17}$

\section{Private Sector in Bio-Conservation}

\footnotetext{
${ }^{15}$ Supra Note 3

${ }^{16}$ Supra Note 11

${ }^{17}$ Supra Note 14
} 
The need for funding is a critical component of conservation. GEF is already proved to be inadequate to meet the challenge as a financial mechanism. Moreover, depending on voluntary contribution lacks sustainability. So there is an increasing consensus that the objectives of the CBD may not be fully achieved without the effective participation of the private sector. If we investigate the decisions taken by COPs on additional financial resources, it will be seen that the COP is relentlessly urging the GEF to take into consideration seriously the potential of private sector involvement from its very earlier meetings. Despite constant urge by the COP, the private sector has long been had no incentive to collaborate with GEF activities. In 1996 and in 1999, this lack of private sector involvement in GEF operations was recognized and the Secretariat submitted two proposals for Council consideration aimed at increasing the role and importance of the private sector in the GEF. ${ }^{18}$ But no substantial measure has taken place pursuant to those.

The problem of biodiversity lies in the external uncompensated benefits that diverse resources render to the global community. This can be compared to unquantified benefits that an inventor does not get. So, why should private investors be interested to invest in the conservation projects of biodiversity? Another barrier for the private sector is the time consuming and complex project approval procedure of the GEF. Given the uncertainty, the risks, the high costs, and the limited amount of funds that are usually made available, private companies do not have many incentives to wait two or more years for project approval. ${ }^{19}$

To some optimists about private sector involvement, the market of environment technology is set to be one of few major growth industries over the next few decades. Prospects appear good for many of the green pioneers: demand exceeds supply in organic agriculture with eco-tourism as the fastest growing market segment of the industry. ${ }^{20}$ Although fiscal measures are still not a primary contributor to the environment policy, positive incentives are increasingly taking a lion's share of the tax system in the Netherlands. The

18 GEF Strategy for Engaging the Private Sector, GEF/C.7/12, March 7, 1996; Engaging the Private Sector in GEF Activities, GEF/C.13/Inf.5 May 14, 1999.

${ }^{19}$ Porter Gareth, Raymond Clemencon, Waafas Ofosu-Amaah, and Michael Philips, Communicative Structure and Governance of the Global Environment Through Policy Networks of International Aid Organizations, 1998

${ }^{20}$ C.O. Bartel and Deborah Vorhies, Insights from the UNEP Financial Service Initiative, presented at a workshop on Financial Innovations for Biodiversity, Bratislava, Slovakia 1-3 May 1998 
revenue in green taxes increased from US\$ 150 million to over US\$2,00,00 million in ten years. ${ }^{21}$ On the other hand, citizens are encouraged to invest in green projects. This is encouraged by offering fiscal incentives like tax exemption. $^{22}$

Another suggested strategy, which is supposed to leave natural capital intact, is "Bio-prospecting" providing an 'incentive' by encouraging countries to view genetic diversity as a source of potential profits. Examples include an agreement between Costa Rica's Instituto Nacional de Biodiversidad and Merck and Company, the world's largest pharmaceutical company. In Suriname, a Bio-prospecting initiative included indigenous healers, a local pharmaceutical company, Misouri botanical gardens, Bristol Myers Squibb Company and the environmental group Conservation International. ${ }^{23}$

Despite all the above, there are reasons for one to be suspicious about private sector involvement in biodiversity conservation. Our experience suggests that private sector has already done immeasurable damage to global biodiversity. Coffee cultivation and logging in the African rain forests caused and are still causing inestimable loss to the richest biodiversity in the world. And these examples form only a part of a vast history of massive biodiversity destruction. It is popularly said that the motto of business ethics is "there is no ethics in business". So we have to ponder seriously whether we shall invite such 'ethical' Multinational Corporations, already having awful records in biodiversity destruction, in 'protection business'.

Eco-tourism is thought to be the most potential field for private sector involvement. But it also offers one of the most potential threats to conservation of biodiversity. Though the situation is not alarming as such today, but it shows all the possibilities to be so in near future. Environmentalists are already raising voice against the proliferation of so called bio-friendly eco-tourism.

And what about "Bio-prospecting" proposed by C.O. Bartel and Deborah Vorhies and also substantiated by illustrations? Exploitation opportunities

${ }^{21}$ Dr. Willem Vermeend, Jacob van der Vaart, Greening taxes, The Dutch Model, Deventer, 1998

${ }^{22}$ Chapter 5, Implementation of incentive measures and context, by Expert Group on Economic Aspects in Biodiversity Green Investment Funds: Organic Farming OECD Paris 20-21 January 1998

${ }^{23}$ Supra Note 20 
provided to TNCs in the field of biotechnological resources could be suicidal. We already have experienced the misappropriation of traditional biotechnological knowledge by these TNCs. Should we risk losing our ageold and traditional knowledge and practice in the name of facilitating private sector to conserve biological diversity?

\section{General Observations}

Apparently, the designation of the GEF as the financial mechanism of the $\mathrm{CBD}$, its restructuring debate and little progress towards restructuring - all depict the financial mechanism of the CBD as an abortive one. Its inefficiency is criticized even in our SAARC forum. ${ }^{24}$ Though new-age international organizations possess some features of legal personality, we must not forget that any Convention's entity is necessarily characterized by its member countries. So, for any deficiency in a financial mechanism, it is not the wording or technical weakness of a given Convention to be blamed but the lack of sufficient political will, especially on the part of the developed countries, is primarily responsible for it. One statistics would lend support reaching this conclusion. Slovenia, Sweden, Spain, Finland and Ireland these are the only donating countries to GEF which fulfilled their donation pledge till date. ${ }^{25}$

\footnotetext{
${ }^{24}$ See SAARC Summit Declaration, held in New Delhi, 1995

${ }^{25}$ For details visit: http://www.gefweb.org
} 